\title{
STUDI PENGENDALIAN BANJIR DAN GENANGAN PADA SISTEM DRAINASE KALI PUCANG SIDOARJO
}

\author{
Dwi Retnowati, Umboro Lasminto, Yang Ratri Savitri \\ Jurusan Teknik Sipil, Fakultas Teknik Sipil dan Perencanaan, Institut Teknologi Sepuluh Nopember (ITS) \\ Jl. Arief Rahman Hakim, Surabaya 60111 Indonesia \\ Email: dweeimmortal@ rocketmail.com
}

\begin{abstract}
Abstrak - Kali Pucang termasuk di dalam kawasan Sub DAS Pucang yang memiliki panjang \pm 26 km mulai dari hulu Kali Pucang (pertemuan Kali Bader dan Kali Suko) sampai ke hilir di selat Madura. Kali Pucang merupakan saluran yang paling parah ketika terjadi banjir. Banjir yang sering terjadi di kali Pucang Sidoarjo ini disebabkan karena curah hujan yang tinggi pada musim hujan namun kapasitas tampung di saluran Kali Pucang tidak mampu menerima debit air yang mengalir, begitu juga dengan kapasitas drainase di permukiman penduduk yang tidak memadai dan ditambah dengan keadaan daerah disekitar Kali Pucang yang merupakan Permukiman yang cukup padat.

Dikarenakan banjir yang terjadi secara terus-menerus setiap tahunnya maka kawasan Kali Pucang perlu dilakukan kajian tentang pengendalian banjir pada sistem drainasenya. Kajian yang dilakukan ini bertujuan untuk mengetahui cara penanggulangan banjir yang terjadi di Kali Pucang, Analisa yang dilakukan adalah dengan menghitung curah hujan menggunakan rumus Log Pearson Tipe III didapatkan besarnya curah hujan yang mungkin terjadi sebesar $118.946 \mathrm{~mm}$. Debit rencana Q10 yang dihitung menggunakan metode Nakayasu menghasilkan debit pada muara Kali Pucang sebesar 103,569 m²/dtk. Kemudian debit banjir yang terjadi akan dibandingkan dengan kapasitas Kali Pucang untuk mengetahui kondisi fullbank pada penampang saluran. Untuk analisa Hidrolika digunakan program bantu HecRas dengan asumsi aliran tidak tetap (unsteady flow).

Dari kajian dan perhitungan yang telah dilakukan, alternatif yang digunakan sebagai pengendalian banjir di Kali Pucang adalah dengan melakukan normalisasi pada saluran dengan 2 cara yaitu normalisasi dengan cara memperlebar penampang sungai dan menambah kedalaman sungai. Sehingga diharapkan dengan adanya normalisasi yang dilakukan dapat mengurangi banjir pada daerah Kali Pucang.
\end{abstract}

Kata kunci : Banjir, Kali Pucang, Sistem Drainase Sidoarjo.

\section{PENDAHULUAN}

Sebuah kota yang layak dan nyaman untuk dijadikan tempat tinggal harus mempunyai beberapa prasarana pendukung kehidupan salah satunya prasarana sistem drainase. Sistem drainase yang tertata rapi dikelola dan dipelihara dengan baik akan dapat memenuhi fungsifungsinya dengan baik. Tetapi pada kenyataannya banyak pembangunan permukiman yang tidak memperhatikan sistem drainasenya, sehingga dapat menimbulkan suatu masalah yaitu banjir. Banjir didefinisikan sebagi debit air sungai yang relatif lebih besar daripada biasanya dan menyebabkan limpahan air sungai yang mengisi dan menggenangi daerah-daerah rendah. Banjir ini juga merupakan masalah yang seringkali terjadi di kawasan Kali Pucang Sidoarjo. Banyak faktor yang menjadi penyebab banjir di kali Pucang Sidoarjo. Data daerah yang terkena dampak banjir Kali Pucang dapat dilihat pada tabel 1.1.
Tabel 1 Tinggi dan Waktu Genangan Banjir Tahun 2013 di Kabupaten Sidoarjo.

\begin{tabular}{|l|l|l|l|}
\hline \multicolumn{2}{|l|}{ Lokasi } & $\begin{array}{l}\text { Waktu } \\
\text { Genangan } \\
\text { (jam) }\end{array}$ & $\begin{array}{l}\text { Tinggi } \\
(\mathrm{cm})\end{array}$ \\
\hline Kabupaten & Desa & 48 & 70 \\
\hline Sidoarjo & Lebo & 48 & 30 \\
\hline & Bluru Kidul & 48 & 30 \\
\hline & Pucang & 48 & 30 \\
\hline & Sidokare & 48 & 40 \\
\hline & Rangkah Kidul & 48 & 60 \\
\hline & Sumberrejo & 24 & 50 \\
\hline & Kemiri & 24 & 40 \\
\hline & Urangagung & 24 & 30 \\
\hline & Siwalan Panji & 24 & 30 \\
\hline & Cemengbakalan & 24 & 30 \\
\hline & Sumput & 24 & 30 \\
\hline & Sidodadi & 24 & 40 \\
\hline & Suko & 24 & 60 \\
\hline & Cangkring Turi & 24 & 50 \\
\hline & Jd. cangkring & 24 & 30 \\
\hline & Popoh & 24 & 30 \\
\hline & Mulyodadi & 24 & 30 \\
\hline & Wonoayu & Konoayu &
\end{tabular}

Sumber : Data sekunder Dinas PU Pengairan Kab. Sidoarjo Th.2013.

\section{PERUMUSAN MASALAH}

1. Bagaimana kondisi banjir dan genangan di DAS Kali Pucang?

2. Berapa debit yang mengalir Kali Pucang ?

3. Bagaimana kapasitas aliran kali Pucang ?

4. Bagaimana cara penanggulangan banjir Kali Pucang? 


\section{TINJAUAN PUSTAKA}

\section{ANALISA HIDROLOGI \\ Data Hujan}

Data yang digunakan adalah data pada Stasiun hujan Sidoarjo, Sumput, Klagen, Ketintang dan Watu Tulis dengan data selama 25 tahun dari tahun 1988 sampai tahun 2012.

\section{Analisa Hujan Rata-rata DAS}

Perhitungan curah hujan rata-rata dari beberapa stasiun menggunakan cara Thiessen Polygon.

\section{Analisa Frekuensi}

Curah hujan rencana untuk periode ulang 10 tahun dicoba dengan menggunakan distribusi frekuensi Gumbel dan Log Pearson tipe III.

\section{Pemeriksaan Kesesuaian Distribusi Frekuensi}

Pemeriksaan kesesuaian distribusi frekuensi tersebut memerlukan pengujian parameter, yaitu : Smirnov Kolmogorov dan Chi Kuadrat

\section{Perhitungan Distribusi Hujan Jam-Jaman}

Untuk perhitungan debit dengan menggunakan rumus hidrograf satuansintetis diperlukandata hujan jam-jaman. Distribusi cuah hujan jamjaman dapat dihitung dengan rumus:

$$
R_{t} \quad=R_{\mathrm{O}} \cdot\left(\frac{T}{t}\right)^{2 / 3}
$$

Perhitungan Debit (Q) Banjir Rencana

Perhitungan debit rencana sangat diperlukan untuk memperkirakan besarnya debit hujan maksimum yang sangat mungkin pada periode tertentu. Dan metode yang digunakan adalah metode perhitungan debit Hidograf metode Nakayasu. Adapun rumus yang digunakan adalah sebagai berikut :

$$
Q_{p}=\frac{A \times R_{0}}{3,6 \times\left(0,3 \times T_{p}+T_{0,3}\right)}
$$

Dimana :

$Q_{p} \quad=$ Debit puncak banjir $\left(\mathrm{m}^{3} / \mathrm{dt}\right)$

$A=$ Luas DAS (km2)

$T_{p} \quad=$ Tenggang waktu dari permulaan hujan sampai puncak banjir (jam)

$T_{0,3} \quad=$ Waktu yang diperlukan oleh penurunan debit, dari debit puncak menjadi 30\% dari debit puncak (jam).

(Hidrologi Teknik, Soemarto,1999)
Untuk mendapatkan $T_{P}$ dan $T_{0,3}$ digunakan rumus empiris:

Bila $\mathrm{L}>15 \mathrm{~km} \quad t_{g}=0,4+0,058 \mathrm{~L}$

Bila $\mathrm{L}<15 \mathrm{~km} \quad t_{g}=0,21 x L^{0,70}$

$T_{P}=t_{g}+O, 8 t_{r}$

$T_{O, 3}=\alpha . t_{g}$

Pada kurva naik $\left(0<t<T_{P}\right)$

$Q=\left(\frac{t}{T_{P}}\right)^{2,4} \times Q_{P}$

Pada kurva turun $\left(T_{P}<\mathrm{t}<T_{P}+T_{0,3}\right)$

$Q=0,3^{\left(\frac{t-T_{P}}{T_{0,3}}\right)} \times Q_{P}$

Pada kurva turun $\left(T_{\mathrm{P}}+T_{0,3}<t<T_{P}+T_{0,3}+1,5\right.$

$T_{0,3)}$

$Q=0,3^{\left(\frac{t-T_{P}+0,5 T_{0,3}}{1,5 T_{0,3}}\right)} \times Q_{P}$

Pada kurva turun $\left(t>T_{P}+T_{0,3}+1,5 T_{0,3}\right)$

$Q=0,3^{\left(\frac{t-T_{P}+0,5 T_{0,3}}{2 T_{0,3}}\right)}$

(Hidrologi Teknik, Soemarto, 1999)

\subsection{ANALISA HIDROLIKA}

\subsubsection{Kapasitas Saluran}

Kapasitas saluran dihitung berdasarkan rumus :

$Q=\frac{1}{n} \cdot R^{2 / 3} \cdot i^{1 / 2} \cdot A$

Dimana :

$Q=$ Debit saluran, satuan meter kubik per $\operatorname{detik}\left(\mathrm{m}^{3} / \mathrm{det}\right)$.

$n=\quad$ Koefisien kekasaran Manning.

$R=$ Jari-jari hidrolis saluran $(\mathrm{m})$.

$I=$ Kemiringan saluran

$A=$ Luas penampang saluran $\left(\mathrm{m}^{2}\right)$.

h

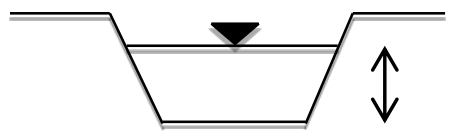

$\mathrm{b}$

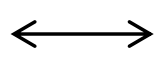

$A=(b+m \cdot h) \cdot h$

$P=b+2 h\left(m^{2}+1\right)^{0,5}$

$R=\frac{A}{P}=\frac{(b+m \cdot h) \cdot h}{b+2 h \cdot\left(m^{2}+1\right)^{0,5}}$

\section{Analisa Permodelan Hec-Ras}

Analisa hidrolika dalam pengerjaannya dilakukan dengan menggunakan program bantu . Program bantu HEC-RAS 4.1.0 ini menggunakan asumsi dua jenis aliran steady atau unsteady dan akan memberikan desain dari hasil kalkulasi analisa hidrolika tersebut. 
Studi Pengendalian Banjir dan Genangan Pada Sistem Drainase Kali Pucang Sidoarjo

\section{Langkah Pengendalian Banjir Dengan Cara $=76 \mathrm{~mm}$ \\ Normalisasi Sungai}

Jenis normalisasi sungai berdasarkan pekerjaan yang dilakukan dibagi menjadi 2 yaitu :

a.Normalisasi dengan cara memperlebar penampang sungai. Langkah ini dapat dilakukan jika daerah sekitar sungai masih memiliki lahan yang cukup. Artinya tidak mengganggu tata guna lahan yang telah ada.

b. Menambah kedalaman sungai. Langkah ini dimaksudkan menambah kapasitas sungai dengan memperdalam sungai dari kedalaman awal.

\section{METODOLOGI}

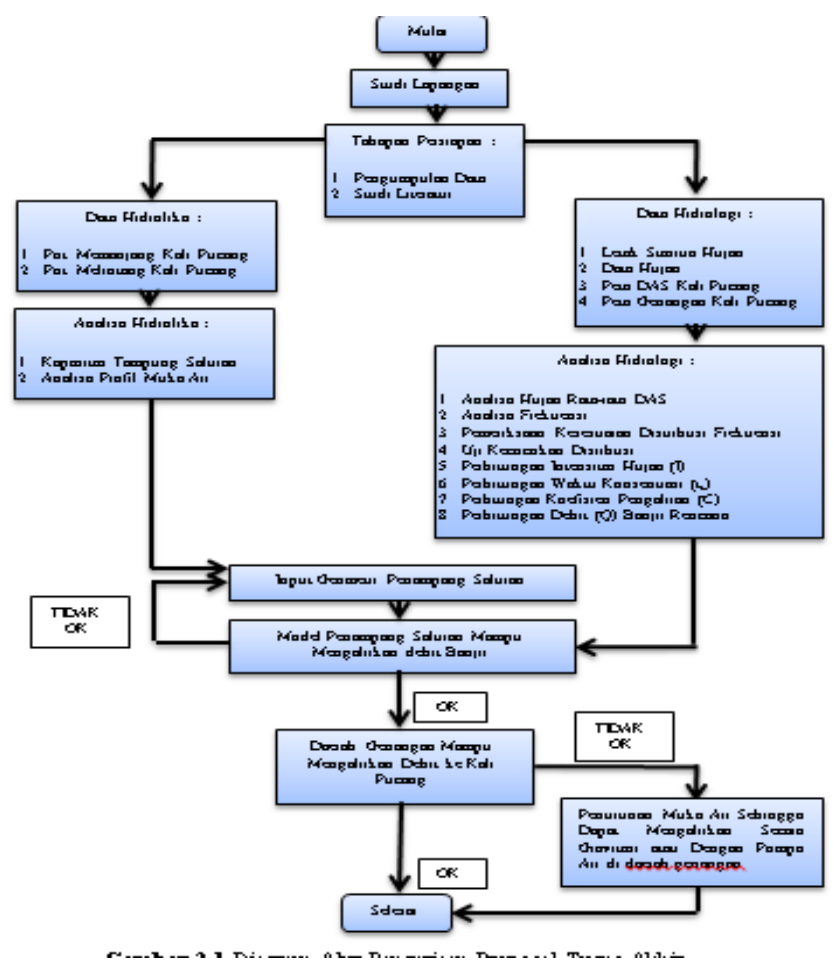

Gambar 1 Diagram Alur Pengerjaan Proposal Tugas Akhir.

\section{HASIL DAN PEMBAHASAN}

\section{ANALISA HIDROLOGI \\ Data Hujan}

Data curah hujan yang digunakan data pada Stasiun hujan Sidoarjo, Sumput, Klagen, Ketintang dan Watu Tulis dengan data 25 tahun dari tahun 1988 sampai tahun 2012.

Analisa Hujan Rata-Rata DAS

$\bar{R}=W_{1} \cdot R_{1}+W_{2} \cdot R_{2}+W_{3} \cdot R_{3}+W_{4} \cdot R_{4}+W_{5}$.

$R_{5}$

$\bar{R}=0,28.83+0,15.0+0,12.81+0,18.82+$ $0,26 \cdot 105$

\section{Perhitungan Distribusi}

Distribusi Gumbel

Jumlah Data $(\mathrm{N}) \quad=25$

Reduce Mean $(\mathrm{Yn}) \quad=0,5299$

Reduce Standart Deviasi $(\mathrm{Sn})=1,0876$

periode ulang 10 tahun maka dihitung

$Y_{t}=-\ln \left[-\ln \cdot \frac{9}{10}\right]=2,2504$

Nilai Rata-rata $(\bar{X})=\frac{\sum X}{n}=\frac{2474}{25}=98,949$

Standart Deviasi $(S)=\sqrt{\frac{\sum(X-\bar{X})^{2}}{(n-1)}}=\sqrt{\frac{5529,98}{24}}=$ 15,179

persamaan untuk distribusi Gumbel :

$$
\begin{aligned}
& X=\bar{X}+\frac{Y t-Y n}{S n} \cdot S \\
& X=98,949+\frac{2,2504-0,5299}{1,0876} \cdot 15,179 \\
& =122,961 \mathrm{~mm}
\end{aligned}
$$

Tabel 2 Perhitungan Curah Hujan Rencana untuk Periode Ulang $(\mathrm{T})$ dengan Metode Distribusi

\begin{tabular}{|c|c|c|c|}
\hline Tahun & Yt & K & $X$ \\
\hline 2 & 0.3665 & 0.1502 & 96.668 \\
\hline 5 & 1.4999 & 0.8919 & 112.487 \\
\hline 10 & 2.2504 & 1.5819 & 122.961 \\
\hline
\end{tabular}
Gumbel

\section{Tabel 2 Hasil Perhitungan Distribusi Gumbel}

Distribusi Log Pearson Tipe III

Nilai rata-rata (mean) :

$\overline{\log X}=\frac{\sum \log X}{n}=\frac{49,770}{25}=1,991$

Standar deviasi :

$\overline{S \log X}=\sqrt{\frac{\sum(\log X-\overline{\log X})^{2}}{(n-1)}}=\sqrt{\frac{0,0971}{24}}=0,064$

Faktor Frekuensi $(k): \frac{(1,328-1,333)}{(k-1,333)}=\frac{(0,600-0,700)}{(0,624-0,700)}$ $=1,329$

$\log X=\overline{\log X}+k \cdot S \log$

$\log X=1,991+1,329.0,064$

$X=118,946 \mathrm{~mm}$ 
Tabel 3 Perhitungan Curah Hujan Rencana untuk Periode Ulang (T) dengan Metode Distribusi Log Person Tipe III

\begin{tabular}{|c|c|c|c|c|c|}
\hline $\begin{array}{l}\text { Tah } \\
\text { un }\end{array}$ & $\log R=\frac{\sum \log g}{n}$ & $\begin{array}{l} \\
\log \\
\end{array}$ & $K$ & $\begin{array}{l}\log \\
X\end{array}$ & $X$ \\
\hline 2 & $\begin{array}{l}1.99 \\
1\end{array}$ & $\begin{array}{l}0.06 \\
4\end{array}$ & $\begin{array}{l}- \\
0.10 \\
31\end{array}$ & $\begin{array}{l}1.98 \\
4\end{array}$ & $\begin{array}{l}96.44 \\
0\end{array}$ \\
\hline 5 & $\begin{array}{l}1.99 \\
1\end{array}$ & $\begin{array}{l}0.06 \\
4\end{array}$ & $\begin{array}{l}0.79 \\
76\end{array}$ & $\begin{array}{l}2.04 \\
2\end{array}$ & $\begin{array}{l}110.0 \\
37\end{array}$ \\
\hline 10 & $\begin{array}{l}1.99 \\
1\end{array}$ & $\begin{array}{l}0.06 \\
4\end{array}$ & $\begin{array}{l}1.32 \\
92\end{array}$ & $\begin{array}{l}2.07 \\
5\end{array}$ & $\begin{array}{l}118.9 \\
46\end{array}$ \\
\hline
\end{tabular}

\section{Uji Kecocokan Sebaran}

hasil Uji Kecocokan untuk menentukan persamaan distribusi yang dipakai ditampilkan dalam Tabel 4.26. berikut :

Tabel 4 Kesimpulan Uji Kecocokan

\begin{tabular}{|c|c|c|c|c|c|c|c|c|}
\hline \multirow{3}{*}{$\begin{array}{l}\text { Pers } \\
\text { ama } \\
\text { an } \\
\text { Dist } \\
\text { ribu } \\
\text { si }\end{array}$} & \multicolumn{8}{|c|}{ Uji Kecocokan } \\
\hline & \multicolumn{4}{|c|}{ Chi - Kuadrat } & \multicolumn{4}{|c|}{$\begin{array}{l}\text { Smirnov } \\
\text { Kolmogorov }\end{array}$} \\
\hline & $\begin{array}{l}X \\
h^{2}\end{array}$ & $\begin{array}{l}\mathrm{N} \\
\text { il } \\
\mathrm{a} \\
\mathrm{i}\end{array}$ & $\underset{2}{X}$ & Ket & $\begin{array}{l}D_{m} \\
\text { aks }\end{array}$ & $\begin{array}{l}\mathrm{N} \\
\text { il } \\
\text { ai }\end{array}$ & $\begin{array}{l}\mathrm{D} \\
\mathrm{o}\end{array}$ & Ket \\
\hline $\begin{array}{l}\mathrm{Gu} \\
\mathrm{mbe} \\
1\end{array}$ & $\begin{array}{l}2 \\
3, \\
6 \\
0\end{array}$ & $>$ & $\begin{array}{l}5 \\
9 \\
9 \\
1\end{array}$ & $\begin{array}{l}\text { Tida } \\
\mathrm{k} \\
\mathrm{Me} \\
\text { men } \\
\text { uhi }\end{array}$ & $\begin{array}{l}0,0 \\
69\end{array}$ & $<$ & $\begin{array}{l}0 \\
2 \\
7 \\
0\end{array}$ & $\begin{array}{l}\text { Me } \\
\text { men } \\
\text { uhi }\end{array}$ \\
\hline $\begin{array}{l}\text { Log } \\
\text { Pear } \\
\text { son }\end{array}$ & $\begin{array}{l}3, \\
2 \\
0\end{array}$ & $<$ & $\begin{array}{l}5 \\
9 \\
9 \\
1\end{array}$ & $\begin{array}{l}\text { Me } \\
\text { men } \\
\text { uhi }\end{array}$ & $\begin{array}{l}0,0 \\
70\end{array}$ & $<$ & $\begin{array}{l}0 \\
2 \\
7 \\
0\end{array}$ & $\begin{array}{l}\text { Me } \\
\text { men } \\
\text { uhi }\end{array}$ \\
\hline
\end{tabular}

Sumber : Hasil Perhitungan

Perhitungan Koefisien Pengaliran Gabungan

$=\frac{\left[C_{1} \cdot A_{1}\right]+\left[C_{2} \cdot A_{2}\right]+\left[C_{3} \cdot A_{3}\right]}{\left[A_{1}+A_{2}+A_{3}\right]}$

$=$

$[0,30.510]+[0,75.395]+[0,30.72]+[0,30.61]+[0,30.20]+[0,75.21]$

$[510,39+394,83+72,24+60,73+20,40+21,47]$

Maka didapatkan Cgabungan $=0,426$

Perhitungan Curah Hujan Effektif Periode Ulang Perhitungan rata-rata hujan $\left(\mathrm{R}_{\mathrm{t}}\right)$ sampai jam ke $\mathrm{t}$ adalah :
Tabel 5 Perhitungan Distribusi Tinggi Hujan Periode Ulang 10 Tahun

\begin{tabular}{|l|l|l|l|l|}
\hline \multirow{2}{*}{$\begin{array}{l}\text { Jam } \\
\text { Ke- }\end{array}$} & \multirow{2}{*}{$\begin{array}{l}\text { Rt } \\
(\mathrm{mm})\end{array}$} & \multirow{2}{*}{\begin{tabular}{l} 
Rt' $^{\prime}(\mathrm{mm})$ \\
\cline { 4 - 5 }
\end{tabular}} & & \multicolumn{2}{|l|}{ Periode Ulang 10 Tahun } \\
\cline { 4 - 5 } & & R24 maks $(\mathrm{mm})$ adalah 118,946 \\
\hline 1 & 0.585 & 0.585 & 69.583 & $\mathrm{Rt}^{\prime}(\mathrm{mm})$ \\
\hline 2 & 0.368 & 0.151 & 43.772 & 69.583 \\
\hline 3 & 0.281 & 0.107 & 33.424 & 17.961 \\
\hline 4 & 0.232 & 0.085 & 27.595 & 12.727 \\
\hline 5 & 0.200 & 0.072 & 23.789 & 10.110 \\
\hline
\end{tabular}

Untuk perhitungan distribusi tinggi hujan effektif diambil contoh perhitungan pada sub catchment sekunder Pager.

Luas DAS $=22,21 \mathrm{~km}^{2}$

$\mathrm{R}_{24} \quad=118,95 \mathrm{~mm}=11,895 \mathrm{~cm}$

Koefisien Pengaliran $=0,426$

$\mathrm{R}_{\text {eff }}=$ Rt x C (koefisien pengaliran)

$\operatorname{Reff}_{(\mathrm{jam} \mathrm{1)}}=69,583 \times 0,426=2,965 \mathrm{~mm}$

$\operatorname{Reff}_{(\text {jam 2) }}=17,961 \times 0,426=0,765 \mathrm{~mm}$

$\operatorname{Reff}_{(\mathrm{jam} 3)}=12,727 \times 0,426=0,542 \mathrm{~mm}$

$\operatorname{Reff}_{(\mathrm{jam} 4)}=10,110 \times 0,426=0,431 \mathrm{~mm}$

$\operatorname{Reff}_{(\text {jam 5) }}=8,564 \times 0,426=0,365 \mathrm{~mm}$

\section{Perhitungan Hidrograf Banjir}

Primer Pucang

Parameter Hidrograf Nakayasu :

$\mathrm{A}=15,49 \mathrm{~km}^{2}=1549$ ha

$\mathrm{L} \quad=15,600 \mathrm{~km}$

$R_{0} \quad=1 \mathrm{~mm}$

$\operatorname{Tr} \quad=1 \mathrm{jam}$

$T_{g} \quad=0,21 \times \mathrm{L}^{0,07}(\mathrm{~L}<15 \mathrm{~km})$

$=0,21 \times 15,600^{0,07}$

$=0,255 \mathrm{jam}$

$T_{p} \quad=T_{g}+(0,8 \times \mathrm{tr})$

$=0,255+(0,8 \times 1)$

$=1,055 \mathrm{jam}$

$a=3$ (untuk bagian naik hidrograf yang cepat dan bagian menurun yang lambat).

$$
\begin{aligned}
& \mathrm{T}_{0,3} \quad=a \times \mathrm{T}_{\mathrm{g}} \\
& =3 \times 0,255 \\
& =0,764 \mathrm{jam} \\
& Q_{p}=\frac{A \times R_{0}}{3,6 \times\left(0,3 \times T_{p}+T_{0,3}\right)} \\
& =\frac{103,90 \times 1}{3,6 \times(0,3 \times 1,055+0,764))} \\
& =3,985 \mathrm{~m}^{3} / d t
\end{aligned}
$$

$\mathrm{Tp}+\mathrm{T}_{0,3}=1,55+0,764=1,818 \mathrm{Jam}$

$\mathrm{Tp}+\mathrm{T}_{0,3}+1,5 \mathrm{~T}_{0,3}=1,055+0,764+(1,5 \times 0,764)$ $=2,964 \mathrm{Jam}$ 
Tabel 6 Pada Waktu Kurva Naik $(0<\mathrm{t}<$ Tp $=\mathbf{1 , 0 5 5}$ )

\begin{tabular}{|l|l|l|}
\hline $\begin{array}{l}t \text { (jam) } \\
\text { (jan }\end{array}$ & $A=\left(\frac{t}{T_{p}}\right)^{2,4}$ & $Q=Q_{p} \times A$ \\
\hline 0.000 & 0.000 & 0.000 \\
\hline 0.500 & 0.168 & 1.620 \\
\hline 1.000 & 0.889 & 8.548 \\
\hline
\end{tabular}

Tabel 7 Pada Waktu Kurva Turun $(T p=1,055$ $<\mathrm{t}<\mathbf{T p}+\mathbf{T}_{\mathbf{0 , 3}}=\mathbf{1 , 8 1 8 )}$

\begin{tabular}{|l|l|l|l|}
\hline$t($ jam $)$ & $\mathrm{A}=(\mathrm{t}-\mathrm{Tp}) / \mathrm{T} 0.3$ & $0,3^{\wedge} \mathrm{A}$ & $Q=Q_{p} \times 0,3^{A}$ \\
\hline 1.500 & 0.60 & 0.49 & 4.670 \\
\hline
\end{tabular}

Tabel 8 Pada Waktu Kurva Turun $(<\mathrm{Tp}+$ $\left.T_{0,3}+1,5 T_{0,3}=2,964\right)$

\begin{tabular}{|c|c|c|c|}
\hline $\begin{array}{c}t \\
(\mathrm{am})\end{array}$ & $A=\frac{\left(\mathrm{t}-T_{p}\right)+\left(1,5 \times T_{0,2}\right)}{\left(2 x T_{0,2}\right)}$ & $0,3^{\mathrm{A}}$ & $Q=Q_{,} x A$ \\
\hline 3.000 & 2.05 & 0.08 & 0.815 \\
\hline 3.500 & 2.38 & 0.06 & 0.546 \\
\hline 4.000 & 2.72 & 0.04 & 0.365 \\
\hline 4.500 & 3.05 & 0.03 & 0.245 \\
\hline 5.000 & 3.38 & 0.02 & 0.164 \\
\hline 5.500 & 3.72 & 0.01 & 0.110 \\
\hline 6.000 & 4.05 & 0.01 & 0.073 \\
\hline 6.500 & 4.38 & 0.01 & 0.049 \\
\hline 7.000 & 4.71 & 0.00 & 0.033 \\
\hline 7.500 & 5.05 & 0.00 & 0.022 \\
\hline 8.000 & 5.38 & 0.00 & 0.015 \\
\hline 8.500 & 5.71 & 0.00 & 0.010 \\
\hline 9.000 & 6.05 & 0.00 & 0.007 \\
\hline 9.500 & 6.38 & 0.00 & 0.004 \\
\hline 10.000 & 6.71 & 0.00 & 0.003 \\
\hline
\end{tabular}

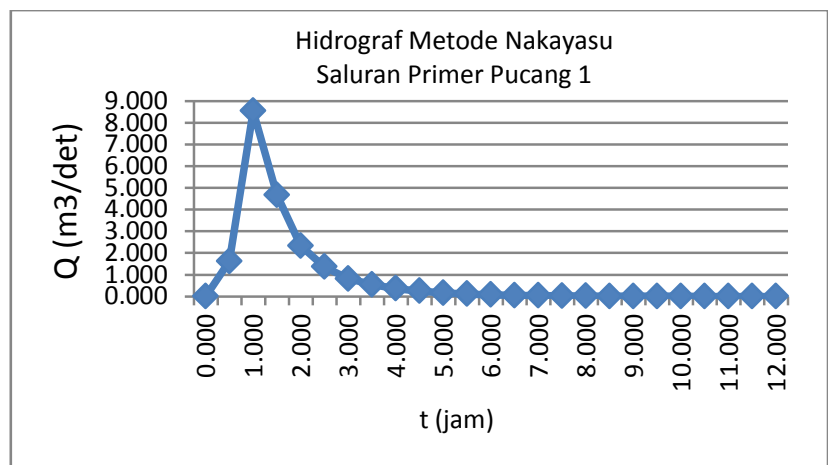

Gambar 2 Unit Hidrograf Nakayasu Periode Ulang 10 Tahun Saluran Primer Pucang 1
Perhitungan Debit (Q) Banjir

\begin{tabular}{|c|c|c|c|c|c|c|c|}
\hline \multirow{3}{*}{$c$} & \multirow{3}{*}{$\begin{array}{l}\text { Debit } \\
\text { im } 3 / d i t\end{array}$} & \multicolumn{5}{|c|}{ Debit alibat hujan netto $(\mathrm{m} 3 / \mathrm{dt})$} & \multirow{3}{*}{$\begin{array}{c}\text { Total } \\
\text { Debii } \\
\text { Ban̈̈11 } \\
\text { tm3/4t }\end{array}$} \\
\hline & & \multirow{2}{*}{$\begin{array}{c}\text { Jam lae } \\
1 \\
3.496 \\
\end{array}$} & \multirow{2}{*}{\begin{tabular}{|l|} 
Jam \\
ke-2 \\
0902 \\
\end{tabular}} & \multirow{2}{*}{$\begin{array}{c}\text { Jam } \\
\text { ke-3 } \\
0.639 \\
\end{array}$} & \multirow{2}{*}{\begin{tabular}{|l} 
Jam \\
ke-4 \\
0508 \\
\end{tabular}} & \multirow{2}{*}{$\begin{array}{c}\begin{array}{c}\text { Jam } \\
\text { ke-5 }\end{array} \\
0.430 \\
\end{array}$} & \\
\hline & & & & & & & \\
\hline 0.000 & 0.000 & 0.000 & & & & & 0.000 \\
\hline 0.500 & 1620 & 5662 & & & & & 5662 \\
\hline 1000 & 8548 & 29886 & 0.000 & & & & 29886 \\
\hline 1500 & 4670 & 16328 & 1.462 & & & & 17.790 \\
\hline 2000 & 2329 & 8.144 & 7.714 & 0.000 & & & 15858 \\
\hline 2500 & 1364 & 4.771 & 4215 & 1036 & & & 10021 \\
\hline 3000 & 0815 & 2850 & 2.102 & 5.466 & 0,000 & & 10.419 \\
\hline 3500 & $0 \leq 46$ & 1908 & 1231 & 2986 & 0.823 & & 6949 \\
\hline 4000 & 0365 & 1278 & 0.736 & 1.490 & 4342 & 0.000 & 7846 \\
\hline 4500 & 0245 & 0.856 & 0.493 & 0873 & 2372 & 0.697 & 5290 \\
\hline 5000 & 0.164 & 0.573 & 0330 & 0.521 & 1.183 & 3678 & 6286 \\
\hline 5500 & 0.110 & 0384 & 0221 & 0349 & 0.693 & 2010 & 3656 \\
\hline 6000 & 0.073 & 0257 & 0.148 & 0234 & 0.414 & 1.002 & 2055 \\
\hline 6500 & 0.049 & 0.172 & 0.099 & 0.156 & 0277 & 0587 & 1292 \\
\hline 7000 & 0.033 & 0.115 & 0.066 & 0.105 & 0.186 & 0351 & 0.823 \\
\hline 7500 & 0.022 & 0.077 & 0.044 & 0.070 & 0.124 & 0235 & 0551 \\
\hline 8.000 & 0.015 & 0.052 & 0.030 & 0.047 & 0.083 & 0.157 & 0369 \\
\hline 8500 & 0.010 & 0035 & 0.020 & 0.031 & 0.056 & 0.105 & 0247 \\
\hline 9000 & 0.007 & 0.023 & 0.013 & 0.021 & 0.037 & 0.071 & 0.165 \\
\hline 9500 & 0.004 & 0.015 & 0.009 & 0.014 & 0.025 & 0.047 & 0.111 \\
\hline 10,000 & 0.003 & 0.010 & 0.006 & 0.009 & 0.017 & 0.032 & 0.074 \\
\hline 10500 & 0.002 & 0,007 & 0.004 & 0.006 & 0.011 & 0.021 & 0.050 \\
\hline 11000 & 0.001 & 0.005 & 0.003 & 0.004 & 0.007 & 0.014 & 0.033 \\
\hline 11500 & 0.001 & 0,003 & 0.002 & 0.003 & 0.005 & 0.009 & 0.022 \\
\hline 12,000 & 0.001 & 0.002 & 0,001 & 0,002 & 0,003 & 0,006 & 0.015 \\
\hline
\end{tabular}

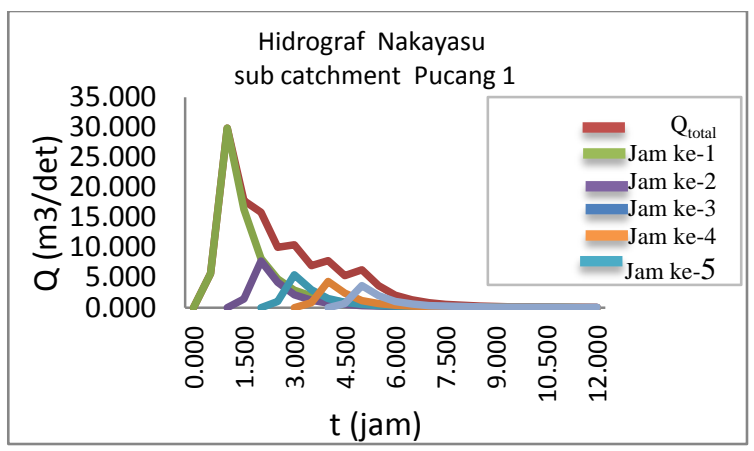

Gambar 3 Hidrograf Nakayasu Sub Catchment Pucang 1

Dari hasil penjumlahan perhitungan debit dari anak sungai yang masuk ke saluran Primer Pucang didapat debit sebesar 103,569 $\mathrm{m}^{3} / \mathrm{dtk}$

\section{ANALISA HIDROLIKA}

\section{Analisa Kapasitas Sungai}

Perhitungan kapasitas sungai dilakukan untuk mengetahui kondisi penampang sungai di lapangan. Diketahui bahwa debit yang mengalir pada Penampang P1 adalah sebesar 37,103 $\mathrm{m}^{3} / \mathrm{dtk}$.

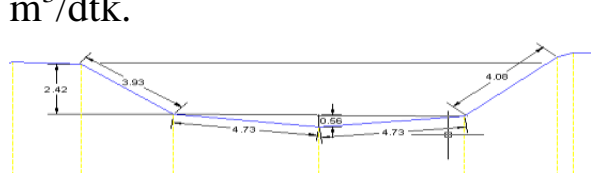


Gambar 3 Penampang Melintang Kali Pucang P1

Luas Penampang I $=0.5 \times(9.40+14.76) \times 2.42=$ 29,934 $\mathrm{m}^{2}$

Luas Penampang II $=0.5 \times 9.40 \times 0.56=2.63$ $\mathrm{m}^{2}$

Luas Penampang total $=31,864 \mathrm{~m}^{2}$

Keliling Penampang $\mathrm{I}=3.93+4.08=8.01 \mathrm{~m}$

Keliling Penampang II $=4.73+4.73=$

$9.46 \mathrm{~m}$

Keliling Penampang total $=17.47 \mathrm{~m}$

Jari-jari Hidrolis $\quad=\frac{A}{P}=\frac{32.638}{17.47}=1.686 \mathrm{~m}$

Kemiringan $=\frac{4.623-3.902}{95.90}=0.000249$

Kekasaran Manning $=0.020$

Kecepatan $=\frac{1}{n} \cdot R^{2 / 3} \cdot i^{0.5}=1,178 \mathrm{~m}^{3} / \mathrm{dtk}$

Kapasitas Sungai $=$ V x A

$$
=1,178 \times 31,864
$$

$=37,536 \mathrm{~m}^{3} / \mathrm{dtk}$

\section{Permodelan Hec-Ras}

Dalam analisa Hec-ras digunakan unsteady flow, dan didapatkan hasil running banyak penampang yang tidak mampu menampung debit banjir yang mengalir.

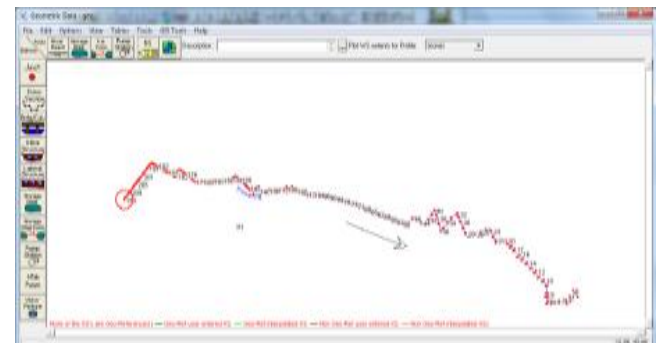

Gambar 4 Skema aliran sungai

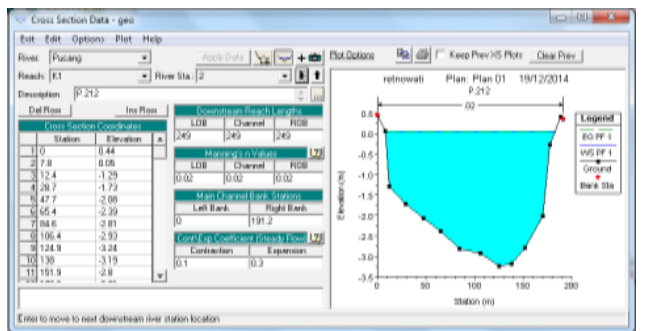

Gambar 5 Profil melintang sungai di P212

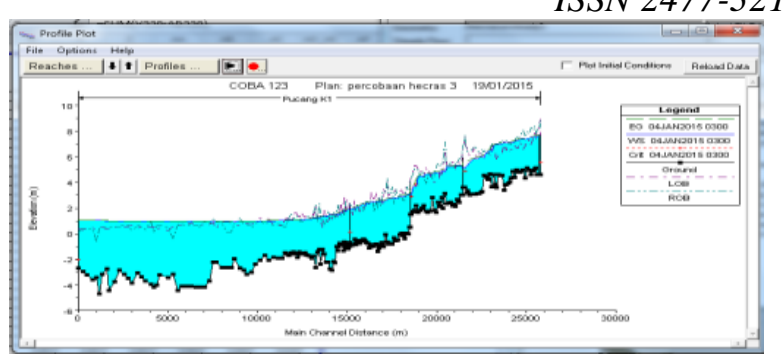

Gambar 6 Profil memanjang sungai

\section{Langkah Pengendalian Banjir}

Setelah didapatkan hasil dari program bantu Hecras, maka dapat dilihat bahwa terdapat beberapa penampang sungai yang tidak mampu menampung debit yang mengalir, sehingga perlu untuk dilakukanya normalisasi. Jenis normalisasi sungai berdasarkan pekerjaan yang dilakukan dibagi menjadi 2 yaitu:

a. Normalisasi dengan cara memperlebar penampang sungai langkah ini dapat dilakukan jika daerah sekitar sungai masih memiliki lahan yang cukup. Artinya tidak mengganggu tata guna lahan yang telah ada.

b. Menambah kedalaman sungai langkah ini dimaksudkan menambah kapasitas sungai dengan memperdalam sungai dari kedalaman awal.

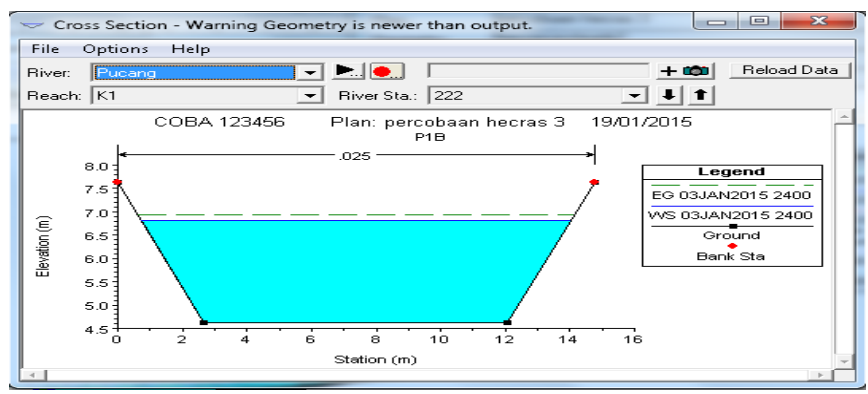

Gambar 7 Profil melintang sungai rencana

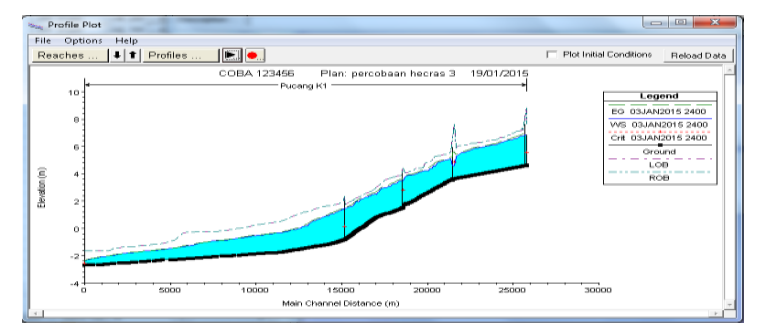

Gambar 8 Profil memanjang sungai rencana

\section{KESIMPULAN}

\section{Kesimpulan}

Dari uraian secara umum dan perhitungan secara teknis pada bab-bab sebelumnya dapat dapat ditarik beberapa kesimpulan sebagai berikut : 
Studi Pengendalian Banjir dan Genangan Pada Sistem Drainase Kali Pucang Sidoarjo

1. Kondisi yang terjadi di Kali Pucang ketika banjir dan genangan terjadi adalah :

a. Terjadi peluapan di saluran Kali

Pucang ketika hujan dan penampang saluran tidak mampu menampung debit yang mengalir, sehingga air meluap ke daerah permukiman warga. Banjir di sekitar Kali Pucang sendiri bisa terjadi selama $24-48$ jam lamanya.

b. Banyaknya tanggul yang ambrol dikarenakan tidak mampu menahan luapan air, sehingga memperparah kondisi ketika terjadi banjir.

c. Kurangnya fasilitas pengendalian banjir seperti pompa air, pintu air dan juga bosem pada anak sungai Sidokare dan Kumambang, padahal kedua anak sungai tersebut mempunyai debit besar daripada anak sungai yang lain, sehingga semakin menambah luapan banjir ke Kali Pucang.

Didapatkan debit pada sungai :

Sekunder Bader : 37,103 $\mathrm{m}^{3} / \mathrm{dtk}$.

Sekunder Pager : 7,089 $\mathrm{m}^{3} / \mathrm{dtk}$.

Sekunder Jogopati : $3,498 \mathrm{~m}^{3} / \mathrm{dtk}$

Sekunder Sidokare : 11,692 $\mathrm{m}^{3} / \mathrm{dtk}$

Sekunder Kumambang : 9,966

$\mathrm{m}^{3} / \mathrm{dtk}$

Sekunder Karangbong : 1,436 $\mathrm{m}^{3} / \mathrm{dtk}$

Sekunder Kedungguling : 1,154 $\mathrm{m}^{3} / \mathrm{dtk}$

Primer Pucang $1: 29,886 \mathrm{~m}^{3} / \mathrm{dtk}$

Primer Pucang $2: 20,801 \mathrm{~m}^{3} / \mathrm{dtk}$

Primer Pucang $3: 20,795 \mathrm{~m}^{3} / \mathrm{dtk}$

Dan didapatkan jumlah total debit di muara Kali Pucang adalah sebesar 103,569 $\mathrm{m}^{3} / \mathrm{dtk}$

2. Berdasarkan perhitungan dan program bantu Hec-Ras 4.1.0 didapat bahwa beberapa kapsita penampang saluran Pucang tidak mampu menampung debit yang mengalir.

3. sistem pengendalian banjir yang dilakukan adalah dengan melakukan normalisasi penampang sungai pada penampang yang mengalami luapan dengan cara memperlebar sungai dan menambah kedalaman sungai, sehingga mampu menampung debit yang mengalir.

\section{Saran}

Saran yang diberikan adalah :

1. pengerukan terhadap saluran kali Pucang.

2. Memberikan perkuatan (plengsengan) pada sisi sungai agar tidak terkena gerusan sehingga sering terjadi ambrolnya tanggul.

\section{DAFTAR PUSTAKA}

[1] Anggrahini, Ir., MSc., 2005, Hidrolika Saluran Terbuka, Penerbit: SRIKANDI, Surabaya.

[2] Bambang Triatmodjo, 2006, Hidrologi Terapan, Penerbit : BETA OFFSET, Yogyakarta.

[3] Fifi Sofia, Ir., 2006, Modul Drainase.

[4] Robert J. Kodoatie, 2013, Rekayasa Dan Manajemen Banjir Kota, Penerbit : ANDI, Yogyakarta.

[5] Soemarto, CD.,1999, Hidrologi Teknik, Penerbit:, ERLANGGA, Jakarta.

[6] Suripin, 2004, Sistem Drainase Perkotaan yang Berkelanjutan, Penerbit: ANDI, Yogyakarta.

[7] Sholeh M, 1985, Diktat Hidrologi, Surabaya, ITS.

[8] Subarkah, 1980, Hidrologi Untuk Perencanaan Bangunan Air, Penerbit: IDEA DHARMA, Bandung. 